\title{
ANALISIS NILAI TAMBAH AGROINDUSTRI TEMPE (Rhizopus Oligosporus) (Studi Kasus Pada Perusahaan Bapak Maman di Desa Jalatrang Kecamatan Cipaku Kabupaten Ciamis)
}

\author{
ADDITIONAL VALUE ANALYSIS OF TEMPE AGROINDUSTRY (Rhizopus \\ Oligosporus) \\ (A Case Study at Mr. Maman's Company in Jalatrang Village, Cipaku District \\ Ciamis Regency)
}

\author{
IRFAN HENDRIAWAN ${ }^{1 *}$, DINI ROCHDIANI ${ }^{2}$, BUDI SETIA $^{1}$ \\ ${ }^{1}$ Fakultas Pertanian, Universitas Galuh Ciamis \\ ${ }^{2}$ Fakultas Pertanian Universitas Padjajaran

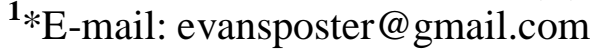

\begin{abstract}
ABSTRAK
Usaha agroindustri tempe pada umumnya merupakan sektor informal dengan skala mikro dan kecil tapi memiliki peran penting dalam mendukung kesejahtraan masyarakat luas, Fakta dilapangan menunjukan bahwa usaha agroindustri tempe meskipun sudah berjalan bertahun tahun, tetapi skala usaha mereka sulit berkembang. Tujuan penelitian ini adalah untuk mengetahui : 1) Besarnya biaya, penerimaan, pendapatan agroindistri tempe di Desa Jalatrang Kecamatan Cipaku Kabupaten Ciamis dalam satu kali proses produksi. 2) Besarnya nilai tambah agroindustri tempe di Desa Jalatrang Kecamatan Cipaku Kabupaten Ciamis dalam satu kali proses produksi. Jenis penelitian yang digunakan adalah studi kasus pada agroindustri tempe di Desa Jalatrang Kecamatan Cipaku Kabupaten Ciamis. Teknik penarikan sampel dalam penelitian ini dilakukan secara purposive sampling yaitu pada agroindustri tempe "Bapak Maman". Hasil penelitian menunjukkan bahwa : 1) Biaya yang dikeluarkan oleh responden agroindustri tempe Bapak Maman Sulaeman dalam satu kali proses produksi yaitu Rp 1.523.568,51, penerimaan yaitu Rp 1.840.000, sehingga memperoleh pendapatan Rp 316.431,49, per satu kali proses produksi. 2) Nilai nilai tambah yang diperoleh pada agroindustri tempe Bapak Maman yaitu Rp 4.322,23 dalam satu kali proses produksi.
\end{abstract}

Kata kunci : Biaya, Penerimaan, Pendapatan, Nilai Tambah, Agroindustri.

\begin{abstract}
Tempe agro-industry in general is an informal sector with micro and small scale but has an important role in supporting the welfare of the wider community. The facts in the field show that tempe agroindustry business has been running for years, but the scale of their business is difficult to develop. The purpose of this study was to determine: 1) The amount of costs, revenues, tempeh agro-income in the Jalatrang Village, Cipaku District, Ciamis Regency in one production process. 2) The magnitude of the added value of tempe agro-industry in Jalatrang Village, Cipaku District, Ciamis Regency in one production process. This type of research is a case study on tempe agro-industry in Jalatrang Village, Cipaku District, Ciamis Regency. The sampling technique in this study was conducted by purposive sampling in the agroindustry of "Mr Maman" tempeh. The results showed that: 1) Costs incurred by Tempe agro-industry respondents Mr. Maman Sulaeman in one production process were Rp. $1.523 .568,51$ revenue was $R p$. 1,840,000, so as to obtain an income of $R p$. 316.431.49, per one production process . 2) The added value obtained from Mr. Maman's tempe agroindustry is $R p$ $4,322.23$ in one production process.
\end{abstract}

Keywords: Cost, Revenue, Revenue, Value Added, Agroindustry. 


\section{PENDAHULUAN}

Indonesia merupakan negara agraris dimana sektor pertanian memiliki peran penting dalam pertumbuhan ekonomi nasional. Hal ini dapat dilihat dari banyaknya penduduk atau tenaga kerja yang hidup atau bekerja di sektor pertanian dan produk nasional berasal dari pertanian. Program pembangunan pertanian diarahkan untuk dapat memberikan pelayanan yang prima kepada petani, sehingga dapat menumbuhkan kesadaran bagi masyarakat untuk berpartisipasi aktif dalam pembangunan pertanian (Rahim dan Hastuti, 2007).

Usaha agroindustri tempe pada umumnya merupakan sektor informal dengan skala mikro dan kecil tapi memiliki peran penting dalam mendukung kesejahtraan masyarakat luas, Fakta dilapangan menunjukan bahwa usaha agroindustri tempe meskipun sudah berjalan bertahun tahun, tetapi skala usaha mereka sulit berkembang(Kuswanti dkk, 2015).

Di Indonesia salah satu produk agroindustri yang masyarakat kenal berbahan baku kacang kedelai adalah tempe tidak seperti makanan tradisonal lain yang biasanya berasal dari China atau Jepang, tempe berasal dari Indonesia (Soehyono dkk,2014). Di Jawa Barat tempe merupakan bahan pangan yang cukup populer dikalangan masyarakat, agroindustri tempe masih dapat berkembang dan memiliki peluang cukup besar, maka munculah beberapa agroindustri untuk pengolahan kedelai salah satunya adalah agroindustri tempe (Wahyuni, 2017).

Nilai tambah adalah suatu perubahan nilai yang terjadi karena adanya perlakuan terhadap suatu input pada suatu proses produksi. Arus peningkatan nilai tambah komoditas pertanian terjadi disetiap mata rantai pasok dari hulu ke hilir berawal dari petani berakhir pada konsumen akhir. Nilai tambah komoditas pertanian dapat dilakukan dengan penyediaan bahan baku berkualitas dan berkesinambungan serta melibatkan para pelaku mata rantai pertama. Komoditas pertanian yang bersifat perishable (mudah rusak) dan bulky (kamba) memerlukan penanganan yang tepat, sehingga produk pertanian siap dikosumsi oleh konsumen. Kegiatan tersebut diantara lain pengolahan, pengemasan, pengawetan, dan mutu manajemen untuk kegunaan menimbulkan nilai tambah sehingga membuat produk pertanian bernilai tinggi (Marimin dkk,2010).

Marimin dan Magfiroh,(2010) menyatakan bahwa nilai tambah (value 
added) adalah pertambahan nilai suatu komoditas karena mengalami proses pengolahan, pengangkutan ataupun penyimpanan dalam suatu produksi. Dalam proses pengolahan nilai tambah dapat diidentifikasikan sebagai selisih antara nilai produk dengan biaya bahan baku input lainnya, tidak termasuk tenaga kerja.

\section{METODE PENELITIAN}

\section{Jenis Penelitian}

Jenis penelitian yang digunakan adalah studi kasus pada agroindustri tempe di Desa Jalatrang Kecamatan Cipaku Kabupaten Ciamis. Menurut Nazir (2011), studi kasus merupakan suatu penelitian yang bersifat mendalam mengenai suatu karakteristik tertentu dari objek penelitian.

\section{Teknik Penarikan Sampel}

Teknik penarikan sampel dalam penelitian ini dilakukan secara purposive sampling dengan penentuan sampel secara sensus yang berarti mengambil seluruh pelaku agroindustri tempe, populasi agroindustri tempe di Desa jalatrang hanya satu yaitu agroindustri tempe Bapak Maman, sehingga diambil sampel untuk penelitian ini adalah agroindustri Bapak Maman.

\section{Teknik Pengumpulan Data}

Data yang dikumpulkan dalam penelitian ini meliputi data primer dan data sekuder. Data primer ialah data yang diperoleh secara langsung dari perajin tempe yang dijadikan responden melalui wawancara. Sedangkan data sekunder adalah data yang diperoleh dari literatur literatur dan data dari instansi atau dinas terkait yang ada hubungannya dengan penelitian ini.

\section{Rancangan Analisis Data}

Untuk mengetahui besarnya biaya, penerimaan, pendapatan dan nilai tambah pada agroindustri tempe di Desa Jalatrang Kecamatan Cipaku Kabupaten Ciamis dilakukan analisis sebagai berikut :

1) Analisis Biaya

Untuk mengetahui besarnya biaya total (total cost) digunakan rumus sebagai berikut (Suratiyah, 2015) :

$\mathrm{TC}=\mathrm{TFC}+\mathrm{TVC}$

Dimana :

TC $=$ Total Cost (Biaya Total $)$

TFC = Total Fixed Cost (Biaya

Tetap Total)

TVC $=$ Total Variable Cost (Biaya Variabel Total)

2) Analisis penerimaan

Untuk mengetahui besarnya penerimaan digunakan rumus sebagai berikut (Suratiyah, 2015) :

$$
\mathrm{TR}=\mathrm{Y} \mathrm{x} \text { Py }
$$

Dimana : 
$\mathrm{TR}=$ Total Revenue $\quad$ Penerimaan

Total)

$\mathrm{Y}=$ Jumlah Produksi

Py = Harga

3) Analisis Pendapatan

Untuk mengetahui besarnya pendapatan digunakan rumus sebagai berikut (Suratiyah, 2015) :

$\mathrm{Pd}=\mathrm{TR}-\mathrm{TC}$

Dimana :

$\mathrm{Pd}=$ Pendapatan

$\mathrm{TR}=$ Total Revenue (Penerimaan

Total)

$\mathrm{TC}=$ Total Cost $($ Biaya Total $)$

4) Untuk menganalisis nilai tambah dihitung dengan rumus Hayami dalam Hapsari (2008). Metode Hayami merupakan metode yang memperkiarakan perubahan nilai bahan baku setelah mendapatkan pengolahan. Nilai tambah yang terjadi dalam proses pengolahan merupakan selisih dari nilai produk dengan biaya bahan baku dan input lainya. Adapun beberapa faktor penentu dalam analisis nlai tambah yaitu

1) Faktor Teknis, mencakup kapasitas dari satu unit usaha,jumlah waktu kerjayang digunakan dan tenaga kerja yang dikerahkan.
2) Faktor Pasar, mencakup harga output, upah tenaga kerja, harga bahan baku dan input lain

\section{HASIL DAN PEMBAHASAN}

\section{Identitas Responden}

berdasarkan hasil penelitian diketahui bahwa responden bernama Maman Sulaeman yang berusia 70 tahun. Menurut Daniel (2003) yang dimaksud dengan penduduk usia non produktif adalah yang berusi lebih dari 64 tahun. Berdasarkan pernyataan tersebut maka diketahui umur responden produsen tempe termasuk dalam usia kerja non produktif.

Tingkat pendidikan formal responden adalah lulusan Sekolah Dasar (SD) dengan pengalaman usaha selama 30 tahun, dan jumlah tanggungan keluarga sebanyak 2 orang.

\section{Analisis Biaya}

Biaya produksi adalah korbanan yang digunakan dalam proses produksi untuk menghasilkan produk yang diukur denga uang. Biaya produksi dalam agroindustri tempe merupakan penjumlahan dari biaya tetap dan variabel yang dikeluarkan.

Biaya tetap yang digunakan dalam agroindustri tempe terdiri atas penyusutan alat dan bangunan, pajak bumi dan bangunan, bunga modal per tahun sebesar $6 \%$. Alat yang digunakan dalam kegiatan 
agroindustri tempe terdiri atas tong plastik, drum, keranjang plastik, rak, kajang, kalo, baskom, citakan, pisau, tungku, dan timbangan. Untuk lebih jelasnya perhitungan rincian biaya tetap pada agroindustri tempe dalam satu kali produksi dapat dilihat pada Tabel 1.

Hasil penelitian menunjukan bahwa ratarata besarnya biaya tetap yang dikeluarkan dalam satu kali produksi adalah penjumlahan dari total penyusutan alat, pajak bumi bangunan, dan bunga modal $\begin{array}{llll}\text { yaitu } & \text { sebesar } & \mathrm{Rp} & 7.788,51\end{array}$ terdiri atas total penysutan alat $\mathrm{Rp}$ 7.441,36 pajak bumi bangunan Rp 194,44 dan bunga modal $\mathrm{Rp} 152,71$, dihitung dalam persatu kali produksi.

Tabel 1. Rincian Biaya Tetap pada Agroindustri Tempe dalam Satu Kali Produksi

\begin{tabular}{llrc}
\hline No & \multicolumn{1}{c}{ Jenis Biaya } & Nilai (Rp) & Persentase(\%) \\
\hline 1 & Penyusutan Alat dan Bangunan & $7.441,36$ & 95,54 \\
2 & Pajak & 194,44 & 2,50 \\
3 & Bunga Modal & 152,71 & 1,96 \\
\hline & Jumlah & $\mathbf{7 . 7 8 8 , 5 1}$ & $\mathbf{1 0 0 , 0 0}$
\end{tabular}

Sumber : Data Primer, diolah

Biaya variabel yang digunakan dalam agroindustri tempe terdiri atas kedelai, kayu bakar, ragi, lilin, plastik, dan tenaga kerja dihitung dalam satuan rupiah dalam satu kali proses produksi. Untuk lebih lengkapnya perhitungan rincian biaya variabel dalam satu kali proses produksi dapat dilihat pada Tabel 2.

Tabel 2. Rincian Biaya Variabel pada Agroindustri Tempe dalam Satu Kali Produksi

\begin{tabular}{llrc}
\hline No & \multicolumn{1}{c}{ Jenis Biaya } & Nilai (Rp) & Persentase(\%) \\
\hline 1 & Sarana Produksi & 1.252 .000 & 82,85 \\
2 & Tenaga Kerja & 260.000 & 17,15 \\
\hline \multicolumn{2}{l}{ Jumlah } & $\mathbf{1 . 5 1 5 . 7 8 0}$ & $\mathbf{1 0 0 , 0 0}$ \\
\hline
\end{tabular}

Sumber : Data Primer, diolah

Hasil penelitian menunjukan bahwa rata-rata besarnya biaya total yang dikeluarkan dalam satu kali produksi adalah penjumnlahan dari biaya tetap dan biaya variabel yaitu sebesar yaitu sebesar Rp 1.523.568,51 terdiri atas biaya tetap $\mathrm{Rp}$ 7788,51 dan biaya variabel Rp 1.515.780.

\section{Analisis Penerimaan dan Pendapatan}

Penerimaan total dari agroindustri tempe dalam satu kali proses produksi adalah sebesar Rp $\quad 1.840 .000$ sedangkan pendapatan agroindustri tempe dalam satu kali produksi adalah sebesar Rp $316.431,49$. 


\section{Analisis Nilai Tambah}

Melalui analisis ini dapat diketahui distribusi nilai tambah terhadap tenaga kerja tempe menggunakan per satuan kilogram kedelai sebagai bahan baku utama. Rata-rata harga bahan baku kedelai pada saat penelitian yaitu Rp $8.200,00$ per kilogram.

Nilai tambah yang diperoleh dari hasil pengurangan nilai output oleh sumbangan input lain dan harga bahan baku. Rata-rata nilai tambah pada agroindustri tempe di Desa Jalatrang Kecamatan Cipaku Kabupaten Ciamis dalam satu kali proses produksi adalah sebesar Rp 4.322,23 per kilogram. Nilai tambah tersebut adalah nilai tambah kotor yang belum memperhitungkan imbalan tenaga kerja. Secara lebih terperinci mengenai perhitungan analisis nilai tambah dapat dilihat pada Tabel 3.

Tabel 3. Analisis Nilai Tambah Tempe

\begin{tabular}{|c|c|c|c|}
\hline No & Variabel & \multirow{2}{*}{ Nilai Simbol } & \multirow{2}{*}{ Perhitungan } \\
\hline I & Output,Input dan Harga & & \\
\hline 1. & Hasil Produksi (Kg/proses produksi) & A & 230 \\
\hline 2. & Bahan baku (Kg/hari) & $\mathrm{B}$ & 135 \\
\hline 3. & Tenaga kerja (HOK/hari) & $\mathrm{C}$ & 5 \\
\hline 4. & Faktor konversi & $\mathrm{d}=\mathrm{a}: \mathrm{b}$ & 1,70 \\
\hline 5. & Koefesien tenaga kerja & $\mathrm{e}=\mathrm{c}: \mathrm{b}$ & 0,03 \\
\hline 6. & Harga produk & $\mathrm{F}$ & 8.000 \\
\hline 7. & Upah rata-rata & $\mathrm{G}$ & 52.000 \\
\hline II & \multicolumn{3}{|l|}{ Pendapatan dan Keuntungan } \\
\hline 8. & Harga bahan baku (Rp/kg) & $\mathrm{H}$ & 8.200 \\
\hline 9. & Sumbangan input lain $(\mathrm{Rp} / \mathrm{kg})$ & I & $1.077,77$ \\
\hline 10. & Nilai output $(\mathrm{Rp} / \mathrm{kg})$ & $\mathrm{j}=\mathrm{dxf}$ & 13.600 \\
\hline 11. & a. Nilai tambah $(\mathrm{Rp} / \mathrm{kg})$ & $\mathrm{k}=\mathrm{j}-\mathrm{h}-\mathrm{i}$ & $4.322,23$ \\
\hline & b. Rasio nilai tambah (\%) & $1 \%=\mathrm{k}: \mathrm{j} \times 100 \%$ & 31,78 \\
\hline 12. & a. Imbalan tenaga kerja & $\mathrm{m}=\mathrm{e} \times \mathrm{g}$ & 1.560 \\
\hline & b. Bagian tenaga kerja (\%) & $\mathrm{n} \% \mathrm{~m}: \mathrm{k} \times 100 \%$ & 36,09 \\
\hline 13. & a. Keuntungan & $\mathrm{o}=\mathrm{k}-\mathrm{m}$ & $2.762,23$ \\
\hline & b. Tingkat keuntungan $(\%)$ & $\mathrm{p}=\mathrm{o}: \mathrm{kx} 100 \%$ & 62,90 \\
\hline III & \multicolumn{3}{|l|}{ Balas Jasa Untuk Faktor Produksi } \\
\hline 14. & Marjin $(10)-(8)(\mathrm{Rp} / \mathrm{kg})$ & $q=j-h$ & 5.400 \\
\hline & a. Pendapatan tenaga kerja (\%) & $r=(m: q) \times 100 \%$ & 28,89 \\
\hline & b. Sumbangan input lain (\%) & $\mathrm{s}=(\mathrm{i}: \mathrm{q}) \times 100 \%$ & 19,95 \\
\hline & c. Keuntungan perusahaan $(\%)$ & $\mathrm{t}=\mathrm{q}: \mathrm{q}) \times 100 \%$ & 51,15 \\
\hline
\end{tabular}

Sumber : Data Primer, diolah 
Berdasarkan banyaknya bahan baku yang digunakan diketahu faktor konversi sebesar 1,70 per kilogram bahan baku yang digunakan, hal ini menujukan bahwa dari satu kilogram kedelai menjadi tempe faktor konversinya sebesae 1,70. Selanjutnya untuk koefesien tenaga kerja sebesar 0,03, hal ini menunjukan bahwa untuk mengolah satu kilogram kedelai membutuhkan koefesieen tenaga kerja sebesar 0,03.

Berdasarkan banyaknya bahan baku yang digunakan dapat diketahui bahwa sumbangan input lain sebesar Rp 19,95 per kilogram, hal ini menunjukan bahwa untuk mengolah satu kilogram kedelai menjadi tempe memerlukan biaya korbanan lain sebesar Rp 19,95.

Nilai output sebesar Rp 13.600 diperoleh dari perkalian antara faktor konversi dengan harga produk. Nilai tersebut menunjukan nilai tempe yang dihasilkan dari pengolahan satu kilogram bahan baku tempe.

Besarnya nilai tambah Rp 4.322,23. Nilai tersebut menunjukan nilai tambah dari hasil pengolaham satu kilogram bahan baku kedelai. Rasio nilai tambah dari pengolahan satu kilogram bahan baku kedelai menjadi tempe adalah 31,78 artinya nilai produk per kilogram sama dengan 31,78 kali lipat dari nilai tambah tersebut.

\section{KESIMPULAN DAN SARAN}

\section{Kesimpulan}

Berdasarkan hasil penelitian maka dapat diambil kesimpulan sebagai berikut :

1) Biaya yang dikeluarkan oleh responden agroindustri tempe Bapak Maman dikeluarkan dalam satu kali produksi adalah penjumlahan dari biaya tetap dan biaya variabel yaitu sebesar yaitu sebesar $\operatorname{Rp} 1.523 .568,51$ terdiri atas biaya tetap $\operatorname{Rp} 7.788,51$ dan biaya variabel $\mathrm{Rp} 1.515 .780$.

2) Penerimaan total yang diperoleh pada agroindustri tempe Bapak Maman dalam satu kali proses produksi yaitu sebesar Rp 1.840.000.

3) Pendapatan total total yang diperoleh pada agroindustri tempe Bapak Maman dalam satu kali proses produksi yaitu sebesar Rp 316.431,49

4) Nilai tambah yang diperoleh pada agroindustri tempe Bapak Maman yaitu Rp 4.322,23 dalam satu kali proses produksi. Nilai tersebut menunjukan nilai tambah dari hasil pengolaham satu kilogram bahan baku kedelai. Rasio nilai tambah dari pengolahan satu kilogram bahan baku kedelai menjadi tempe adalah 31,78 artinya nilai produk per kilogram sama dengan 31,78 kali lipat dari nilai tambah tersebut. 


\section{Saran}

Berdasarkan hasil kesimpulan dan pembahasan, maka saran yang dapat disampaikan bahwa usaha agroindustri tempe Bapak Maman memberikan keuntungan dan nilai tambah sehingga responden di sarankan untuk mempertahankan dan meningkatkan kegiatan usahanya.

\section{DAFTAR PUSTAKA}

Adisarwanto, T. 2008. Kedelai. Penebar Swadaya. Jakarta.

Badan Penelitian Dan Pengembangan Pertanian. 2016. Inovasi Teknologi Agroindustri: Inovasi Teknologi Membangun Ketahanan Pangan Dan Kesejahteraan Petani. litbang.pertanian.go.id.

Daniel. M. 2010. Metodologi penelitian sosial ekonomi. Bumi Aksara. Jakarta.

Dinas Koperasi UMKM Dan Perdagangan, 2020, Ciamis.

Hapsari. H., Djuwendah, E., dan Karyani, T.2008. Peningkatan Nilai Tambah dan Strategi Pengembangan Usaha
Pengolahan Salak Manonjaya "Agrikultura, 19(3).

Ismini. 2010. Analisis Nilai Tambah Dan Strategi Pemasaran Kerpik Singkong Mickey Mouse. Malang Agrika. Vol 4:2 Hal 122

Kusnadi. 2007. Ekonomika Pertanian (Pengantar, Teori dan Kasus). Jakarta: Penebar Swadaya.

Marimin dan Magfiroh . 2010. Aplikasi Teknik Pengambilan Keputusan dalam Manajemen Rantai pasok". Bogor: PT. Penerbit IPB Press

Maulidah S, Kusumawardani F.2011. Nilai Tambah Agroindustri Belimbing Manis (Avverhoa Carambola L.) dan Optimalisasi Output Sebagai Upaya Peningkatan Pendapatan. [Skripsi]. Malang. Jurusan Sosial Ekonomi Pertanian. Universitas Brawijaya.

Nazir 2011. Metode Penelitian. Ghallia Indonesia Bogor

Soehyono. 2014. Analisis Usaha dan Nilai Tambah Agroindustri Tempe.Banjar

Soekartawi. 2010. Agribisnis: Teori dan Aplikasinya. PT.RajaGrafindo Persada.: Jakarta 238 hal.

Soetriono A.S dan Rijanto. 2006. Pengantar Ilmu Pertanian. Bayu Media Malang. 